\title{
Prevalence of electrocardiographic patterns associated with sudden cardiac death in the spanish population aged 40 years or older: results of the OFRECE study
}

\author{
Prevalencia de patrones electrocardiográficos asociados a muerte súbita en la \\ población española de 40 años o más: resultados del estudio OFRECE
}

\author{
Paula Awamleh García ${ }^{\mathrm{a}}$, Joaquín Jesús Alonso Martín ${ }^{\mathrm{a}}$, Catherine Graupner Abad ${ }^{\mathrm{b}}$, \\ Rosa María Jiménez Hernández ${ }^{\mathrm{b}}$, Alejandro Curcio Ruigómez ${ }^{\mathrm{b}}$, Pedro Talavera \\ Calle $^{\mathrm{b}}$, Carmen Cristóbal Varela ${ }^{\mathrm{b}}$, José Serrano Antolín ${ }^{\mathrm{b}}$, Javier Muñiz ${ }^{\mathrm{c}}$, Juan José \\ Gómez Doblas ${ }^{\mathrm{d}}$, Eulalia Roig ${ }^{\mathrm{e}}$, en representación de los investigadores del estudio \\ OFRECE
}

\footnotetext{
${ }^{a}$ Servicio de Cardiología, Hospital Universitario de Getafe, Getafe, Madrid, España

${ }^{b}$ Servicio de Cardiología, Hospital Universitario de Fuenlabrada, Fuenlabrada, Madrid, España

${ }^{c}$ Instituto Universitario de Ciencias de la Salud e Instituto de Investigación Biomédica de A Coruña (INIBIC), Universidad de A Coruña, A Coruña, España

${ }^{d}$ Servicio de Cardiología, Hospital Clínico Universitario Virgen de la Victoria, Málaga, España

${ }^{e}$ Servicio de Cardiología, Hospital de la Santa Creu i Sant Pau, Barcelona, España
}

\begin{abstract}
Introduction and objectives. Some electrocardiographic patterns are associated with an increased risk of sudden cardiac death due to ventricular arrhythmias. There is no information on the prevalence of these patterns in the general population in Spain. The objective of this study was to analyze the prevalence of these patterns and associated clinical and epidemiological factors.

Methods. This subanalysis of the OFRECE study selected a representative sample of the Spanish population aged $\geq 40$ years. We studied the presence or absence of electrocardiographic patterns of Brugada syndrome and QT interval abnormalities. Clinical data and electrocardiograms were available in all participants. Electrocardiograms were evaluated by 2 cardiologists and a third cardiologist was consulted if there was disagreement in the diagnosis. We calculated the weighted prevalence and clinical factors associated with the presence of Brugada-type patterns or QT segment abnormalities.

Results. Overall, 8343 individuals were evaluated (59.2 years, $52.4 \%$ female). There were 12 Brugada cases (type 1, 2 cases; type 2, 10 cases; weighted prevalence, 0.13\%). For corrected QT (QTc) analysis, we excluded participants with left bundle branch block or without sinus rhythm. Weighted prevalences were as follows: short QTc (<340 ms) 0.18\%, borderline QTc (441-469 ms) 8.33\%, long QTc ( $\geq 470 \mathrm{~ms}$ criterion) $1.01 \%$ and long QTc ( $\geq 480$ criterion) $0.42 \%$.

Conclusions. A total of $0.6 \%$ to $1.1 \%$ of the Spanish population aged $\geq 40$ years has an electrocardiographic pattern associated with a higher risk of sudden death (Brugada syndrome, long QT, or short QT).
\end{abstract}

\section{Keywords}

Sudden death; Epidemiology; Long QT syndrome; Tachyarrhythmias 


\section{Resumen}

Introducción y objetivos. Hay patrones electrocardiográficos asociados a mayor riesgo de muerte súbita por arritmias ventriculares. En España no existe información acerca de su prevalencia en la población. El objetivo es estudiar la prevalencia de estos patrones, así como los factores clinicoepidemiológicos asociados a su presencia. Métodos. Subanálisis del estudio OFRECE en el que se estudió la prevalencia de patrones electrocardiográficos de síndrome de Brugada o anomalías del intervalo QT en una muestra representativa de la población española $\geq$ 40 años. Se dispuso de datos clínicos y electrocardiogramas de todos los participantes. Los electrocardiogramas fueron evaluados de forma independiente por 2 cardiólogos y, en caso de desacuerdo, se consultó con un tercero. $\mathrm{Se}$ analizaron las prevalencias ponderadas y los factores clínicos asociados a patrones tipo Brugada o a anomalías del segmento QT.

Resultados. Se evaluó a 8.343 individuos (59,2 años, 52,4\% mujeres) y se detectaron 12 casos de patrón Brugada (tipo 1, 2 casos; tipo 2, 10 casos; prevalencia ponderada, 0,13\%). Para el análisis del QT corregido (QTc) se excluyó a los participantes con bloqueo de rama izquierda o ritmos no sinusales. Las prevalencias ponderadas fueron: QTc corto (<340 ms) 0,18\%, QTc borderline (441-469 ms) 8,33\%, QTc largo (criterio $\geq 470 \mathrm{~ms}) 1,01 \%$ y QTc largo (criterio $\geq 480 \mathrm{~ms}$ ) $0,42 \%$.

Conclusiones. El 0,6-1,1\% de la población española de edad $\geq 40$ años presenta un patrón electrocardiográfico de riesgo de muerte súbita (síndrome de Brugada, QT largo o QT corto).

\section{Palabras clave}

Muerte súbita; Epidemiología; Síndrome de QT largo; Taquiarritmias

\section{INTRODUCTION}

In the past 20 years, some clinical and electrocardiographic syndromes have been found to be associated with a higher risk of sudden cardiac death (SCD) due to ventricular arrhythmia, such as Brugada syndrome $e^{1,2,3,4}$ or short QT syndrome. ${ }^{5,6}$ Other conditions, such as long QT syndrome, ${ }^{7,8}$ were already known and have been described in more detail. These diseases can develop asymptomatically for years, and the prevalence reported by various European studies ranges from $0 \%$ to $6 \%{ }^{9,10}$ for Brugada patterns and $0 \%$ to $0.5 \%$ for short QT interval. ${ }^{11}$ Prevalence studies on long QT interval in the general population are highly heterogeneous, with differences in populations and cutoff points. In clinical practice, long QT syndrome is the most common arrhythmic disorder associated with SCD (35.6\%), followed by Brugada syndrome (32.1\%). ${ }^{12}$ The aim of this study was to investigate a representative sample of the Spanish population to estimate the prevalence of electrocardiographic patterns consistent with Brugada types 1 and 2, long QT interval, and short QT interval.

\section{METHODS}

This project was a substudy of the OFRECE project (Spanish acronym for Observation of Fibrillation and Coronary Disease in Spain) approved by the Clinical Research Ethics Committee at the University Hospital of Basurto and by other hospital or regional committees. The aim was to determine the prevalence of atrial fibrillation (AF) and stable angina in the Spanish population $\geq 40$ years. This cross-sectional study was sponsored by the Research Agency of the Spanish Society of Cardiology and was conducted in the Spanish population $\geq 40$ years assigned to a primary care physician. The study methodology and results have already been described in previous publications. ${ }^{13,} 14$ The primary care physician invited randomly-selected patients (11 831) to participate in the study, $76 \%$ of whom accepted. All participants $(n=8400)$ gave written informed consent. 
The flow chart for OFRECE study participation is described in previous publications. ${ }^{13,14}$ The study was started in Spain in March 2010 and completed in October 2012. All participants were examined by their primary care physician, who completed a form on cardiovascular risk factors and medical history. Patients then underwent an electrocardiogram (ECG), and their weight, height, and blood pressure ( 2 measurements) were measured according to the World Health Organization recommendations described in the current European Society of Cardiology guidelines. ${ }^{15}$ When an undiagnosed heart disease was suspected, an appointment was made for the participant with the coordinating cardiologist. The risk factors and medical history analyzed were defined according to the predefined guidelines of the American College of Cardiology/American Heart Association, ${ }^{16}$ which are attached in Appendix 2 of the supplementary material. A total of 57 people were withdrawn from the analysis due to a lack of key information or an unevaluable ECG, giving a final sample of 8343 people.

All ECGs were read at a central location by a group of 9 cardiologists. The ECGs were randomly assigned to each cardiologist, who performed the initial reading. Afterwards, a second cardiologist independently reviewed all tracings. When they disagreed about a patient, a third observer was included and the final diagnosis was reached by consensus. The diagnostic criteria for each abnormality analyzed are described below.

\section{Corrected QT-QT Interval}

Absolute QT interval was measured by hand in leads IIand $\mathrm{V}_{5}$. When II or $\mathrm{V}_{5}$ measurements were impossible, the interval was taken from $\mathrm{V}_{4}$ or $\mathrm{V}_{6}$ or any lead in which it was more readily defined. Automatic measurement was not considered for 2 reasons: $a$ ) it was not available in all electrocardiographs used in the study and $b$ ) electrocardiographs equipped with automatic measurement options used different algorithms. The Bazett formula (QTc $=\mathrm{QT} / \sqrt{\mathrm{RR}})$ was used to calculate the corrected QT (QTc). Although this formula has limitations (tendency to overestimate QT above 100 beats), it is the most used commonly formula and, therefore, the results can be compared with those of other previously published studies. To analyze QTc intervals in the study population, several categories were established based on available clinical evidence, particularly in terms of prognosis. The long QT categories used are those described by Goldenberg et al., ${ }^{17}$ where the short QTc categories taken as a reference are those by Anttonen et al. ${ }^{18}$ :

- Normal QTc: $340-439 \mathrm{~ms}$

- Borderline QTc: 440-469 ms

- Long QTc: $\geq 470 \mathrm{~ms}^{17,19,20,21}$

- Short QTc: $321-339 \mathrm{~ms}$

- Very short QTc: $\leq 320 \mathrm{~ms}^{11,18,22,23}$.

The analysis excluded individuals with complete left bundle-branch block or with paced or nonsinus rhythms.

Once the results were obtained, the new European Society of Cardiology guidelines on ventricular arrhythmia and sudden cardiac death, ${ }^{24}$ which establish a cutoff for long QT $\geq 480 \mathrm{~ms}$ (class I, level of evidence C). Consequently, the study population data were also reanalyzed with this cutoff point. 


\section{Brugada-type Electrocardiographic Patterns}

Brugada 1 and 2 electrocardiographic patterns were defined according to the 2002 consensus document $^{2}$ :

- Type 1 or coved pattern: convex-descending ST-segment elevation $\geq 2 \mathrm{~mm}$ in more than 1 right precordial lead, followed by negative T-wave.

- Type 2 or saddleback pattern: concave ST-segment elevation $\geq 2 \mathrm{~mm}$ in more than 1 right precordial lead, followed by positive or isobiphasic $\mathrm{T}$ waves.

\section{Statistical Analysis}

Because the sampling process meant that individuals in the population had differing probabilities of being selected, each participant in the final sample was assigned a weight that represented the number of persons from the Spanish population having the same sex, age bracket, and geographic area. ${ }^{25}$ Therefore, the sum of all weights of the sample was equal to the size of the Spanish population $\geq 40$ years. This weighting process was complex and was undertaken in 2 phases, using the methodology described in previous reports on the OFRECE study ${ }^{13,14}$ combined with the procedure proposed by Deville and Särndal ${ }^{26}$ with the "Calibrate" instruction of the Stata statistical package (version 10.1). The 2011 municipal census of inhabitants by sex, age bracket, and geographic area was used as the population for the adjustment and calibration.

All analyses were performed in keeping with the sample design of the study. For all variables analyzed, specific prevalences were calculated by sex and age bracket along with the respective $95 \%$ confidence intervals $(95 \% \mathrm{CI})$.

To identify the factors associated with the abnormalities of interest, odds ratios were estimated after adjustment for age and sex by logistic regression models. A multivariable model including factors with $P<.1$ in the previous analysis was subsequently fitted to identify factors independently associated with the conditions of interest.

Interobserver variability was also analyzed, and agreement was very high in all cases, above $99 \%$. In terms of the consistency of Brugada-type patterns, expected agreement was 0.9947 and observed agreement was 0.9976. The Kappa index was 0.5444 (95\% CI, 0.3667-0.7220). In the case of QTc, cases were noted and reviewed if the observer and reviewer measurements were more than $10 \mathrm{~ms}$ apart (higher observer measurement, $\mathrm{n}=172$; higher reviewer measurement, $\mathrm{n}=37$ ). A third measurement was performed by both, and an agreement was reached. In all other cases (discrepancy $\leq 10 \mathrm{~ms})$, the average value was recorded in the database. These discrepancies in $209(2.5 \%)$ pairs of measurements had a lower clinical impact because only $7(0.08 \%)$ would have changed the patient classification in terms of QTe duration. 


\section{RESULTS}

\section{QT Abnormalities}

A total of 8343 participants completed the protocol, but only 7889 met the inclusion criteria for this analysis (native sinus rhythm and no left bundle-branch block). A total of 243 participants were excluded for AF, 135 for left bundle-branch block, 24 for both conditions, and 52 for nonsinus or unnatural rhythm. Of these, 52.5\% were women with a mean age of 58.3 years. Most of the population (7011 individuals) had a normal QTc interval, thus accounting for $88.9 \%$ and for $90.5 \%$ when weighted by age and sex (95\%CI, 89.5-91.5). In this group, mean QTc was $403.8 \mathrm{~ms}(95 \% \mathrm{CI}$, 402.6-405.0). A total of 763 people had borderline QTc (prevalence of 9.7\%; weighting, 8.3\%; 95\%CI, 7.4-9.3). Mean QTc was $449.3 \mathrm{~ms}$ (95\%CI, 448.5-450.0). A total of 96 participants had a long QTc interval (cutoff $\geq 470 \mathrm{~ms}$ ) (gross prevalence, 1.22\%; weighted prevalence, $1.01 \%$; 95\%CI, 0.68-1.34). In this group, mean QTc was $484.9 \mathrm{~ms}$ (95\%CI, 480.2-489.6). Last, 51 participants had a QTc $\geq 480 \mathrm{~ms}$, with a prevalence of $0.65 \%$ and a weighted prevalence of $0.42 \%$ (95\%CI, 0.26-0.57). Mean QTc was $499.48 \mathrm{~ms}$ (95\%CI, 493.11-505.85). A total of 18 patients had short QTc interval (mean QTc, $333.7 \mathrm{~ms}$; 95\%CI, 331.6-335.9), for a prevalence of $0.23 \%$ and when weighted by age and sex, $0.18 \%(95 \% \mathrm{CI}, 0.08-0.29)$. No patients had very short QTc interval. The characteristics of the population and of participants with QTc disorders are listed in Table 1. The multivariable analysis for QTc disorders (Table 2) showed that age and a history of AF were independently associated with the presence of long QT (cutoff $\geq 470 \mathrm{~ms}$ ). Hypertension was strongly associated in the univariable analysis. A multivariable analysis with cutoff $\geq 480 \mathrm{~ms}$ also identified AF as an independent predictive factor of long QTc. The predictive factors for borderline QTc were age, female sex, hypertension, and diabetes mellitus. The association analysis excluded the patient group with short QTc due to its small size. 
Table 1. Characteristics of the Population With Normal Corrected QT. Population Comparisons: Normal Corrected QT With Borderline Corrected QT, Normal Corrected QT With Corrected QT > 470 ms, and Normal Corrected QT With Corrected QT > $480 \mathrm{~ms}$

\begin{tabular}{|c|c|c|c|c|c|c|c|c|c|}
\hline & $\begin{array}{l}\text { Normal } \\
(\mathrm{n}=7011)\end{array}$ & $\begin{array}{l}\text { Borderline } \\
(\mathrm{n}=763)\end{array}$ & $P$ & $\begin{array}{l}\text { Normal } \\
(\mathrm{n}=7011)\end{array}$ & $\begin{array}{l}\text { QTc }>470 \\
(n=96)\end{array}$ & $P$ & $\begin{array}{l}\text { Normal } \\
(\mathrm{n}=7011)\end{array}$ & $\begin{array}{l}\text { QTc }>480 \\
(n=51)\end{array}$ & $P$ \\
\hline \multicolumn{10}{|l|}{ Sex, \% } \\
\hline Men & 48.3 & 38.7 & \multirow{2}{*}{.002} & 48.3 & 53.1 & \multirow{2}{*}{.570} & 48.3 & 52.4 & \multirow{2}{*}{.661} \\
\hline Women & 51.7 & 61.3 & & 51.7 & 46.9 & & 51.7 & 47.6 & \\
\hline \multicolumn{10}{|l|}{ Age bracket, \% } \\
\hline 40-49 years & 33.9 & 21.9 & & 33.9 & 6.3 & & 33.9 & 10.1 & \\
\hline $50-59$ years & 25.9 & 24.3 & & 25.9 & 18.5 & & 25.9 & 4.1 & \\
\hline $60-69$ years & 19.2 & 19.9 & $<.001$ & 19.2 & 29.3 & $<.001$ & 19.2 & 26.4 & $<.001$ \\
\hline $70-79$ years & 13.6 & 17.9 & & 13.6 & 17.6 & & 13.6 & 31.9 & \\
\hline$\geq 80$ years & 7.4 & 16.8 & & 7.4 & 28.4 & & 7.4 & 27.4 & \\
\hline \multicolumn{10}{|l|}{$C V R F$} \\
\hline Obesity, \% & 32.4 & 42.4 & .002 & 32.4 & 43.9 & .029 & 32.4 & 31.4 & .892 \\
\hline Excess weight, \% & 42.4 & 39.9 & .353 & 42.4 & 31.8 & .068 & 42.4 & 28.4 & .094 \\
\hline BMI, mean, $\mathrm{kg} / \mathrm{m}^{2}$ & 28.3 & 98.4 & .003 & 28.3 & 28.9 & .311 & 28.3 & 27.2 & .294 \\
\hline Hypercholesterolemia, \% & 23.7 & 30.2 & .006 & 23.7 & 30.0 & .218 & 23.7 & 28.6 & .496 \\
\hline Diabetes, $\%$ & 10.7 & 19.1 & $<.001$ & 10.7 & 14.2 & .317 & 10.7 & 22.3 & .016 \\
\hline Current smoker, $\%$ & 23.4 & 21.9 & .523 & 23.4 & 12.5 & .073 & 23.4 & 9.3 & .073 \\
\hline $\mathrm{HT}, \%$ & 42.0 & 57.3 & $<.001$ & 42.0 & 72.1 & $<.001$ & 42.0 & 63.1 & .039 \\
\hline $\mathrm{SBP}$, mean, $\mathrm{mmHg}$ & 129.8 & 137.2 & $<.001$ & 129.8 & 138.4 & $<.001$ & 129.8 & 136.4 & .034 \\
\hline DBP, mean, mmHg & 77.7 & 80.0 & $<.001$ & 77.7 & 79.9 & .138 & 77.7 & 76.5 & .404 \\
\hline \multicolumn{10}{|l|}{ History, \% } \\
\hline Stroke & 3.2 & 3.0 & .839 & 3.2 & 8.0 & .016 & 3.2 & 6.6 & .226 \\
\hline Peripheral artery disease & 2.1 & 2.7 & .331 & 2.1 & 5.2 & .052 & 2.1 & 7.6 & .017 \\
\hline Chronic lung disease & 5.5 & 7.2 & .154 & 5.5 & 14.1 & .015 & 5.5 & 26.2 & $<.001$ \\
\hline Thyroid condition & 6.7 & 8.6 & .226 & 6.7 & 8.2 & .638 & 6.7 & 7.8 & .777 \\
\hline Pacemaker/ICD implantation & 0.2 & 0.4 & .218 & 0.2 & 7.3 & $<.001$ & 0.2 & 3.0 & $<.001$ \\
\hline Ischemic heart disease & 4.2 & 3.9 & .773 & 4.2 & 8.5 & .041 & 4.2 & 14.4 & .001 \\
\hline Prior diagnosis of HF & 1.6 & 3.4 & .015 & 1.6 & 5.2 & .011 & 1.6 & 3.8 & .160 \\
\hline Atrial fibrillation & 1.1 & 1.6 & .230 & 1.1 & 6.1 & $<.001$ & 1.1 & 13.0 & $<.001$ \\
\hline
\end{tabular}

BMI, body mass index; CVRF, cardiovascular risk factors; DBP, diastolic blood pressure; HF, heart failure; HT, hypertension; ICD, implantable cardioverter defibrillator; QTc, corrected QT; SBP, systolic blood pressure. 
Table 2. Multivariable Analysis of the Population With Corrected Borderline QT Compared With Normal QT and of the Population with Corrected QT > 470 ms Compared With Normal QT

\begin{tabular}{|c|c|c|c|}
\hline & OR & $95 \% \mathrm{CI}$ & $P$ \\
\hline \multicolumn{4}{|c|}{ Population with borderline QTc compared with population with normal QTc } \\
\hline Age, $y$ & 1.02 & $1.01-1.03$ & $<.001$ \\
\hline Female & 1.48 & $1.16-1.89$ & .002 \\
\hline Diabetes mellitus & 1.51 & $1.16-1.98$ & .003 \\
\hline Hypertension & 1.36 & $1.07-1.71$ & .010 \\
\hline \multicolumn{4}{|c|}{ Population with QTc > $470 \mathrm{~ms}$ compared with population with normal QTc } \\
\hline Age, y & 1.06 & $1.04-1.09$ & $<.001$ \\
\hline Atrial fibrillation & 3.46 & $1.32-9.03$ & .010 \\
\hline
\end{tabular}

95\%CI, 95\% confidence interval; OR, odds ratio; QTc, corrected QT.

\section{Brugada-type Electrocardiographic Patterns}

The Brugada ECG pattern analysis considered the data of 8343 individuals in the study, identifying 12 patients with Brugada 1 and 2 patterns:

- Two patients had Brugada type 1 (2 women aged 55 and 54 years), giving a prevalence of $0.024 \%$, or $0.01 \%$ when weighted (95\%CI, 0.00-0.04).

- Ten patients had Brugada type 2, yielding a prevalence of $0.12 \%$, or $0.17 \%$ when weighted by age and sex (95\%CI, 0.02-0.33). Eight of these were men; mean age of the group was 55.4 years.

Table 3 shows the clinical characteristics of participants with an electrocardiographic pattern consistent with Brugada 1 and 2 compared with those of the general population. The geographic distribution of patients is shown in Figure. 
Table 3. Characteristics of the Population With and Without Brugada Syndrome (Types 1 and 2)

\begin{tabular}{|c|c|c|c|c|}
\hline & \multicolumn{3}{|c|}{ Brugada 1 and 2} & \multirow[t]{2}{*}{$P$} \\
\hline & All $(\mathrm{n}=8343)$ & Yes $(n=12)$ & No $(n=8331)$ & \\
\hline \multicolumn{5}{|l|}{ Sex, $\%$} \\
\hline Men & 47.6 & 50.0 & 47.6 & \multirow{2}{*}{.785} \\
\hline Women & 52.4 & 50.0 & 52.4 & \\
\hline \multicolumn{5}{|l|}{ Age bracket, \% } \\
\hline 40-49 years & 31.2 & 21.7 & 31.2 & \multirow{5}{*}{.165} \\
\hline $50-59$ years & 24.6 & 36.1 & 24.5 & \\
\hline $60-69$ years & 19.3 & 5.7 & 19.3 & \\
\hline $70-79$ years & 14.9 & 0.0 & 14.9 & \\
\hline$\geq 80$ years & 10.1 & 36.5 & 10.0 & \\
\hline \multicolumn{5}{|l|}{$C V R F$} \\
\hline Obesity, \% & 33.8 & 13.2 & 33.9 & .092 \\
\hline Excess weight, \% & 42.1 & 69.7 & 42.0 & .307 \\
\hline BMI, mean, $\mathrm{kg} / \mathrm{m}^{2}$ & 28.4 & 27.6 & 28.4 & .293 \\
\hline Hypercholesterolemia, $\%$ & 25.4 & 10.7 & 25.4 & .133 \\
\hline Diabetes mellitus, $\%$ & 12.2 & 0.0 & 12.2 & .300 \\
\hline Current smoker, $\%$ & 22.3 & 8.7 & 22.4 & .630 \\
\hline Hypertension, $\%$ & 45.3 & 51.8 & 45.3 & .853 \\
\hline $\mathrm{SBP}$, mean, mmHg & 130.9 & 139.1 & 130.8 & .424 \\
\hline DBP, mean, mmHg & 77.8 & 76.1 & 77.8 & .077 \\
\hline \multicolumn{5}{|l|}{ History, \% } \\
\hline Stroke & 3.8 & 0.0 & 3.8 & .578 \\
\hline Peripheral artery disease & 2.4 & 0.0 & 2.4 & .662 \\
\hline Chronic lung disease & 6.3 & 0.0 & 6.3 & .462 \\
\hline Thyroid condition & 6.9 & 2.8 & 6.9 & .254 \\
\hline Pacemaker/ICD implantation & 0.7 & 0.0 & 0.7 & .829 \\
\hline Ischemic heart disease & 4.9 & 4.7 & 4.9 & .704 \\
\hline Prior diagnosis of $\mathrm{CHF}$ & 3.1 & 0.0 & 3.1 & .620 \\
\hline Atrial fibrillation & 4.4 & 0.0 & 4.4 & .554 \\
\hline
\end{tabular}

BMI, body mass index; CHF, congestive heart failure; CVRF, cardiovascular risk factors; DBP, diastolic blood pressure; ICD, implantable cardioverter defibrillator; SBP, systolic blood pressure. 


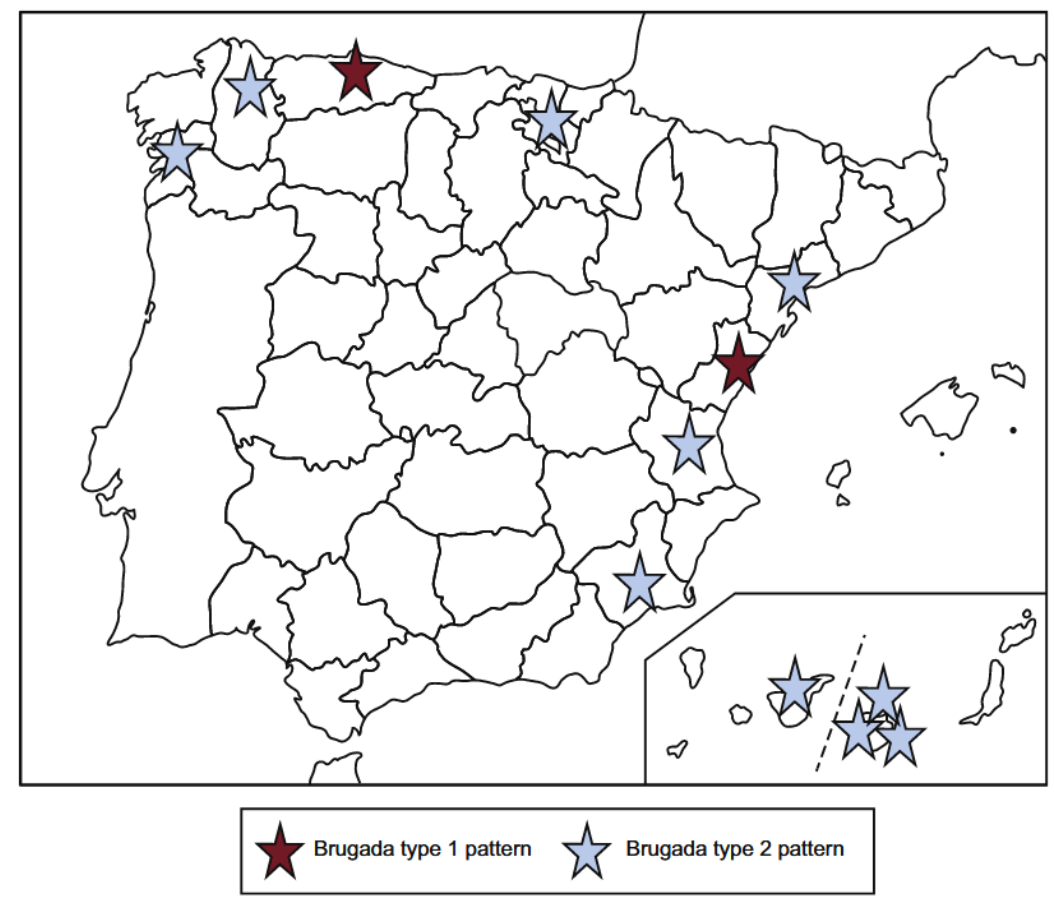

Figure. Geographic distribution of the Brugada-type the electrocardiographic patterns found.

\section{DISCUSSION}

This cross-sectional study in a representative sample of the Spanish population aged $\geq 40$ years found a prevalence of $0.01 \%$ for Brugada type 1 pattern, $1.01 \%$ for long QTc interval defined as $\geq$ $470 \mathrm{~ms}$ or $0.42 \%$ when defined as $\geq 480 \mathrm{~ms}$, and $0.18 \%$ for short QTc. Consequently, we found that electrocardiographic abnormalities associated with SCD were present in a nonnegligible percentage of the general population. Based on the results, it was estimated that $0.6 \%$ to $1.2 \%$ of the population $\geq$ 40 years old has an electrocardiographic pattern associated with a higher risk of SCD. If patients with borderline QTc and Brugada type 2 pattern are also considered, this percentage would be nearly $10 \%$.

Patterns Associated With Brugada Syndrome

The prevalence found for Brugada 1 and 2 patterns was low $(0.13 \%)$, a finding consistent with the European series published after 2002 in Greece, Italy, and Turkey. ${ }^{27,}{ }^{28,}{ }^{29}$ In northern countries (Germany, Finland, and Denmark), ${ }^{10,30,31}$ the prevalence was low and no Brugada type 1 pattern was observed. In our study, it is noteworthy that the 2 cases of Brugada type 1 corresponded to 2 middleaged women, even though Brugada syndrome is traditionally considered to affect men more often, at a ratio of $8: 1 .^{2}$ In this regard, the findings of patients with Brugada type 2 patterns are more consistent with the medical literature ( 8 of the 10 patients reported were men). Our study determined prevalence only for individuals older than 40 years. However, in terms of prognosis, this selection bias may be of some importance because the above reviews report a mean age of 40 years for onset or diagnosis among affected patients. 


\section{QT Abnormalities}

The prevalence of QT abnormalities was high. According to Goldenberg et al., ${ }^{17}$ borderline QTc or QTc above $470 \mathrm{~ms}$ is associated with a higher risk of cardiac events. The prevalences found in this series are high: $8.3 \%$ and $1.01 \%(\geq 470 \mathrm{~ms})$, respectively. Therefore, we can estimate that almost 4 million people in Spain have some degree of QTc interval prolongation and are thus at risk of cardiac events. However, other studies have shown even higher prevalences. Veglio et al. ${ }^{20}$ reported a gross prevalence of $25.8 \%$ of people with QTc > $440 \mathrm{~ms}$. This cohort was small and selective: all participants had type 2 diabetes, mean age was 65.4 years, and most were women. Because QTc elongation is significantly related to age, female sex, and a diagnosis of diabetes, this alone explains why these authors observed higher prevalences than those obtained in the present study. The Rotterdam study ${ }^{21}$ also found much higher prevalences than those obtained in our study: $18 \%$ had borderline QTc and $11.1 \%$ had long QTc. Again, the mean age of the population analyzed was higher and there were more women than men. Furthermore, the cutoff points used were much more restrictive than those used in our study; consequently, all these factors may have contributed to the differences found between the 2 analyses. In our study, among affected patients, the long QT group showed a different clinical pattern than the group with borderline QTc. Borderline QTc identifies individuals with a high cardiovascular risk burden, whereas factors such as diabetes and hypertension are independent predictors. Cardiovascular risk burden had no influence on whether the patient had long QTc. In this case, QTc elongation above 470 or $480 \mathrm{~ms}$ was strongly associated with prior episodes of AF. Regarding the potential role of antiarrhythmic drugs in this context, only 2 of the patients with a history of AF were receiving amiodarone or an HF class drug, and it was unknown how many participants were receiving these drugs for other arrhythmias; hence, it was not possible to accurately establish the percentage of individuals receiving antiarrhythmic therapy that might explain the presence of long QT. Regardless of any pharmacological effects, there may be unidentified characteristics in these individuals that cause QT elongation (eg, genetic factors related to congenital long QT syndrome) and be predisposing factors for AF. As in previous studies, borderline QTc was significantly related to age and female sex. ${ }^{17,20,21}$ This was not true of long QTc, which was related to age but not sex.

The prevalence of short QTc was $0.23 \%$ - somewhat lower than the prevalences published in Japanese series ${ }^{32,33}$ and more in line with European series ${ }^{11,18}$-, due to the cutoff used in this case (340 ms or less).

Based on the results, more information is clearly needed on the true prognosis of these findings. A follow-up study in these populations will help identify patients who will benefit from more specific clinical follow-up.

\section{Limitations}

\section{Limitations Related to Sample Selection}

Although the cross-sectional design with random selection of participants from the general population is not an efficient design under conditions of very low prevalence (particularly in the case of Brugada syndrome), this study was possible as part of the OFRECE project. As previously indicated, this study provides reasonable proof that it adequately represents the Spanish population $\geq$ 40 years. ${ }^{13}$ It is probable that, in conditions related to early mortality (such as Brugada syndrome), the true prevalence is underestimated when only persons surviving to age 40 are included. Consequently, the magnitude of the problem presented here probably is most likely an underestimation of the true prevalence. 
Another limitation concerns the technique used to acquire the tracings. It is known that ECGs must be done according to specific standards. Our study was unable to control for correct use of highpass and low-pass filters, paper speed, voltage, etc, and it was necessary to analyze ECGs obtained with several different electrocardiographs. This may have influenced some diagnoses; however, a more rigorous approach would have been too costly and complex, and would have jeopardized the feasibility of the study. Nevertheless, these technical limitations meant that the study more closely represents real clinical practice. Some of these limitations were corrected by analyzing the ECGs in a centralized manner.

The intermittent nature of some disorders is another limitation. For instance, the prevalence of Brugada pattern may have been underestimated because it is sometimes seen only under certain circumstances (fever or use of some drugs). In the case of long QT, we were unable to identify patients with QT elongation that was drug-induced or due to a congenital abnormality. Information on pharmacological therapies in this patient group was limited to data on drugs used in AF, and no information was available on the use of antihypertensives, antibiotics, antiepileptics, or other drugs implicated in QT elongation. Consequently, we were unable to identify patients with long QT interval in whom drugs were not implicated.

\section{CONCLUSIONS}

Electrocardiographic patterns associated with SCD are common in the Spanish population aged 40 years or older: $0.6 \%$ to $1.1 \%$ have some electrocardiographic abnormality associated with a higher risk of SCD due to ventricular arrhythmia, thus representing a total of 480000 people with the condition in Spain. In our study, long QTc interval was the most common finding (0.42\% to $1 \%$ of patients according to the cutoff used) and was associated with a prior history of AF and with older age. Borderline QTc - also associated with SCD, although to a lesser extent - showed a high prevalence (8.3\%), or around 3332000 persons aged 40 years or older in Spain. This condition was associated with older age, female sex, and cardiovascular risk factors (hypertension and diabetes). Brugada type 1 pattern showed very low prevalence $(0.01 \%)$, similar to that described in other series in our setting.

\section{FUNDING}

The OFRECE study was sponsored by the Research Agency of the Spanish Society of Cardiology. The study was funded by a grant from the Women's Observatory of the Quality Agency of the Ministry of Health and by an unrestricted grant from SANOFI (which did not participate in the study design, data analysis, or manuscript preparation).

\section{CONFLICTS OF INTEREST}

None declared. 


\section{REFERENCES}

1. Brugada P, Brugada J. Right bundle branch block, persistent ST segment elevation and sudden cardiac death: A distinct clinical and electrocardiographic syndrome: A multicenter report. J Am Coll Cardiol. 1992;20:1391-6.

2. Wilde AA, Antzelevitch C, Borggrefe M, et al. Proposed diagnostic criteria for the Brugada syndrome: consensus report. Circulation. 2002;106:2514-9.

3. Antzelevitch C, Brugada P, Borggrefe M, et al. Brugada syndrome. Report of the second consensus conference. Circulation. 2005;111:659-70.

4. Antzelevitch C. Brugada syndrome. Pacing Clin Electrophysiol. 2006;29:1130-59.

5. Gussak I, Brugada P, Brugada J, et al. Idiopathic short QT interval a new clinical syndrome?. Cardiology. 2000;94:99-102.

6. Gaita F, Giustetto C, Bianchi F, et al. Short QT syndrome: a familial cause of sudden death. Circulation. 2003;108:965-70.

7. Medeiros-Domingo A, Iturralde-Torres P, Ackerman MJ. Clínica y genética en el síndrome de QT largo. Rev Esp Cardiol. 2007;60:739-52.

8. Van Noord C, Eijgelsheim M, Stricker BH. Drug and non-drug-associated QT interval prolongation. Br J Clin Pharmacol. 2010;70:16-23.

9. Hermida JS, Lemoine JL, Aoun FB, et al. Prevalence of the brugada syndrome in an apparently healthy population. Am J Cardiol. 2000;86:91-4.

10. Sinner MF, Pfeufer A, Perz S, et al. Spontaneous Brugada electrocardiogram patterns are rare in the German general population: results from the KORA study. Europace. 2009;11:1338-44.

11. Bjerregaard P, Nallapaneni H, Gussak I. Short QT interval in clinical practice. $J$ Electrocardiol. 2010;43:390-5.

12. Hocini M, Pison L, Proclemer A, et al. Scientific Initiative Committee, European Hear Rhythm Association. Diagnosis and management of patients with inherited arrhythmia syndromes in Europe: results of the European Heart Rhythm Association Survey. Europace. 2014;16:600-3.

13. Gómez-Doblas JJ, Muñiz J, Alonso Martin JJ, et al. Prevalencia de fibrilación auricular en España. Resultados del estudio OFRECE. Rev Esp Cardiol. 2014;67:259-69.

14. Alonso JJ, Muñiz J, Gómez-Doblas JJ, et al. Prevalencia de angina estable en España. Resultados del estudio OFRECE. Rev Esp Cardiol. 2015;68:691-9.

15. Mancia G, De Backer G, Dominiczak A, et al. Guidelines for the management of arterial hypertension The Task Force for the Management of Arterial Hypertension of the European Society of Hypertension (ESH) and of the European Society of Cardiology (ESC). Eur Heart J. 2007;28:1462-536.

16. McNamara RL, Brass LM, Drozda JP, et al. ACC/AHA key data elements and definitions for measuring the clinical management and outcomes of patients with atrial fibrillation. A report of the American College of Cardiology/American Heart Association Task Force on Clinical Data Standards (Writing Committee to Develop Data Standards on atrial Fibrillation). J Am Coll Cardiol. 2004;44:475-95.

17. Goldenberg I, Moss AJ, Bradley J, et al. Long-QT syndrome after age 40. Circulation. 2008;117:2192-201.

18. Anttonen O, Junttila MJ, Rissanen $\mathrm{H}$, et al. Prevalence and prognostic significance of short QT interval in a middle-aged Finnish population. Circulation. 2007;116:714-20.

19. Schwartz PJ, Stramba-Badiale M, Crotti L, et al. Prevalence of the congenital long-QT syndrome. Circulation. 2009;120:1761-7.

20. Veglio M, Bruno G, Borra M, et al. Prevalence of increased QT interval duration and dispersion in type 2 diabetic patients and its relationship with coronary heart disease: a population-based cohort. J Intern Med. 2002;251:317-24.

21. Straus SM, Kors JA, De Bruin ML, et al. Prolonged QTc interval and risk of sudden cardiac death in a population of older adults. J Am Coll Cardiol. 2006;47:362-7.

22. Gollob MH, Redpath CJ, Roberts JD. The Short QT Syndrome. Proposed Diagnostic Criteria. J Am Coll Cardiol. 2011;57:802-12.

23. Bjerregaard P. Proposed Diagnostic Criteria for Short QT Syndrome Are Badly Founded. J Am Coll Cardiol. 2011;58:549-50.

24. Priori SG, Blomstrom-Lundqvist C, Mazzanti A, et al. 2015 ESC Guidelines for the management of patients with ventricular arrhythmias and the prevention of sudden cardiac death: The Task Force for the Management of Patients with Ventricular Arrhythmias and the Prevention of Sudden Cardiac Death of the European Society of Cardiology (ESC). Endorsed by: Association for European Paediatric and Congenital Cardiology (AEPC). Eur Heart J. 2015;36:2793-867. 
25. Silva LC. Diseño razonado de muestras y captación de datos para la investigación sanitaria. Madrid: Díaz de Santos;2000.

26. Deville JC, Särndal CE. Calibration estimators in survey sampling. J Am Statist Assoc. 1992;87:376-82.

27. Letsas KP, Gavrielatos G, Efremidis M, et al. Prevalence of Brugada sign in a Greek tertiary hospital population. Europace. 2007;9:1077-80.

28. Gallagher MM, Forleo GB, Behr ER, et al. Prevalence and significance of Brugada-type ECG in 12,012 apparently healthy European subjects. Int J Cardiol. 2007;130:44-8.

29. Bozkurt A, Yas D, Seydaoglu G, et al. Frequency of Brugada-type ECG pattern (Brugada sign) in Southern Turkey. Int Heart J. 2006;47:541-7.

30. Junttila MJ, Raatikainen MJ, Karjalainen J, et al. Prevalence and prognosis of subjects with Brugada-type ECG pattern in a young and middle-aged Finnish population. Eur Heart J. 2004;25:874-8.

31. Pecini R, Cedergreen $\mathrm{P}$, Theilade $\mathrm{S}$, et al. The prevalence and relevance of the Brugadatype electrocardiogram in the Danish general population: data from the Copenhagen City Heart Study. Europace. 2010;12:982-6.

32. Funada A, Hayashi K, Ino H, et al. Assessment of QT Intervals and Prevalence of Short QT Syndrome in Japan. Clin Cardiol. 2008;31:270-4.

33. Miyamoto A, Hayashi H, Yoshino T, et al. Clinical and electrocardiographic characteristics of patients with short QT interval in a large hospital-based population. Heart Rhythm. 2012;9:66-74. 